\title{
Sport participation in Victoria, 2017 Research summary
}

This summary outlines key findings and insights from the third year of VicHealth and Sport and Recreation Victoria's joint research into organised community sport participation in Victoria across 12 popular sports including Australian football, basketball, bowls, cricket, football (soccer), golf, gymnastics, hockey, netball, sailing, swimming and tennis. It illustrates participation across age, sex and location in 2017 and compares this with participation in 2015 and 2016.

\section{Key findings at a glance: organised sport participation in Victoria, 2017}

Participation in sport increased by more than 125,700 participants ( $1 \%$ increase in the participation rate) between 2015-2017. This was approximately equal for male and female participation. are aged between 4-14 years. Sport participation is highest among young children (aged 5-14 years) and drops significantly during adolescence (Figure 1).

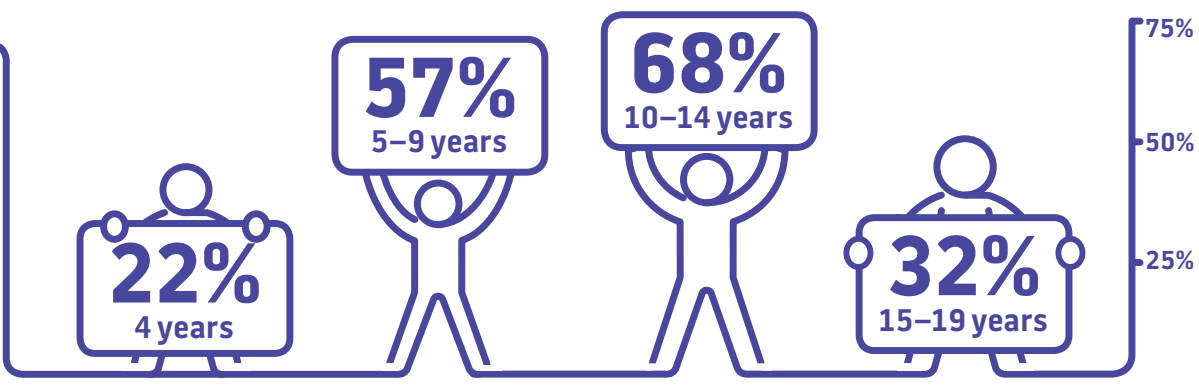

Sport participation rates among females are half of those among males. From 2015 to 2017 there was a considerable increase in female participation in some traditionally male dominated sports, mainly within the 5-19 year age groups (Figure 2).
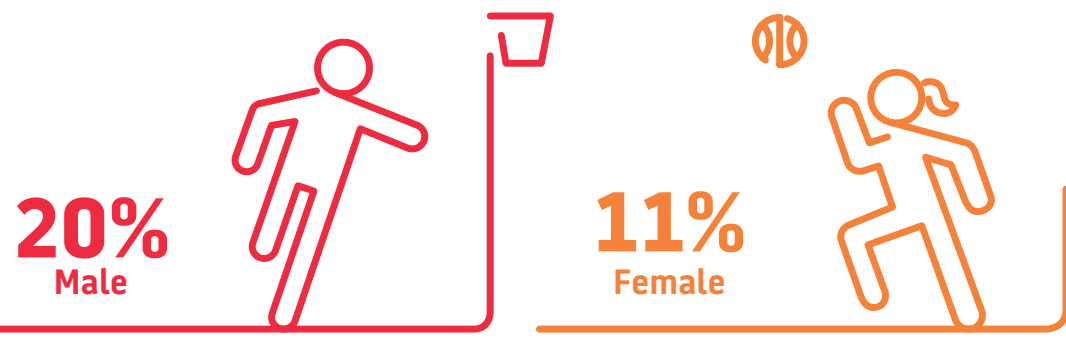

Sport participation rates are higher in regional Victoria compared to metropolitan Melbourne (Figure 3). Metropolitan growth areas also have a lower sport participation level than other metropolitan regions.
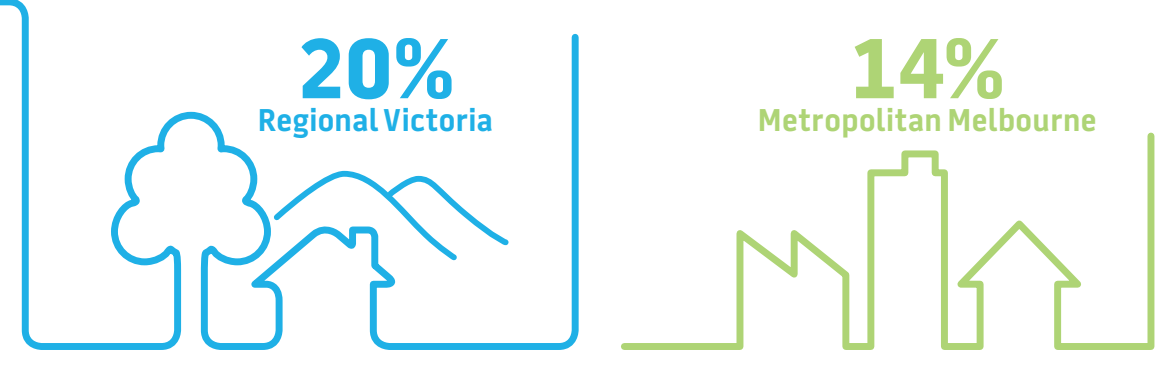

Participation data collection of sporting organisations can significantly fluctuate in quality both across sports and in the same sport from year to year. 
2017

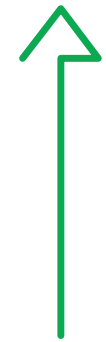

8 sports

Eight sports increased their total numbers in 2017 compared to 2015.
8 sports

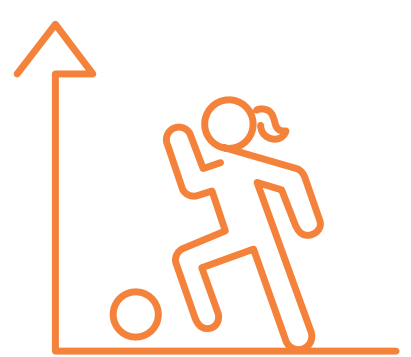

4 sports

Eight sports had an increased participation rate for females in 2017 compared to 2015.

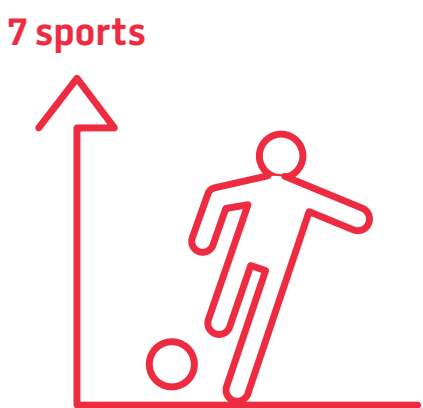

5 sports

Seven sports had an increased participation rate for males in 2017 compared to 2015.

\section{COMPARATIVE FINDINGS 2015-2017}

- The overall participation numbers increased each year from 2015-2017, with 125,765 more sports participants in 2017 compared to 2015. This corresponds to a participation rate increase of approximately $1 \%$.

- The largest growth in participation rates 2015-2017 were within the 10-14 year age group with an increase of $4.6 \%$, followed by $15-19$ years with an increase of $3.1 \%$.

- The largest growth in participation rate for females were within the 5-9 year age group with an increase of $6.4 \%$ followed by 10-14 year age group with an increase of $5.5 \%$.

- The largest growth in participation rate for males were within the 15-19 year age group with an increase of $4.3 \%$ followed by the $10-14$ year age group with an increase of $3.7 \%$.

- The profile of sport participation in Victoria changed little between 2015 and 2017. However, the highest participation rate increase was for participants aged 5-19 in 2017 compared to 2015.

- There was a considerable increase in female participation in some traditionally male-dominated sports such as AFL, soccer and cricket, mainly within the 5-19 year age groups.

\section{Local government snapshot}

- The area with highest participation growth was in the Regional - growth area with an overall increase of $2.4 \%$, males an increase of $3.0 \%$ and females $1.8 \%$. The Metropolitan - other area had an overall increase of $1.4 \%$ and very similar for males and females. The Regional other area had an overall increase of $1 \%$ and very similar for males and females. The Metropolitan - growth area had the lowest overall growth of $0.1 \%$ and decrease rate for males of -0.3 and a slight increase for females of $0.5 \%$.

- There is considerable variation in overall participation rates in these 12 sports across local government areas (Table 1 ). An understanding of how participation rates differ can inform local planning for facilities, programs and overall approach to increasing physical activity. However, this information should be considered in conjunction with other available data to build a total picture of the needs of the community. Lower participation rates do not necessarily mean the area has lower overall physical activity levels, it may mean, for instance that there is a lack of sporting facilities and instead the community has higher rates of walking, cycling or other active recreation.

- The highest overall sport participation rate was 39\% in Buloke Shire, in the Regional - other area. The highest participation rates in the other areas were: Regional - growth: Surf Coast, 29\%; Metropolitan - other: Bayside, 29\%; and Metropolitan - growth: Cardinia 15\%.

- The lowest participation rate was 6\% in Greater Dandenong, in the Metropolitan - other area. The lowest participation rates in the other areas were: Metropolitan - growth: Melton, 9\%; Regional - other: Wodonga, 15\%; and Regional - growth; Moorabool, 17\% (Figure 4).

- Generally, participation is higher in the Metropolitan east and south-east compared to western suburbs (Figure 5). 
Figure 1. Participation rates, 2017, Victoria: by age

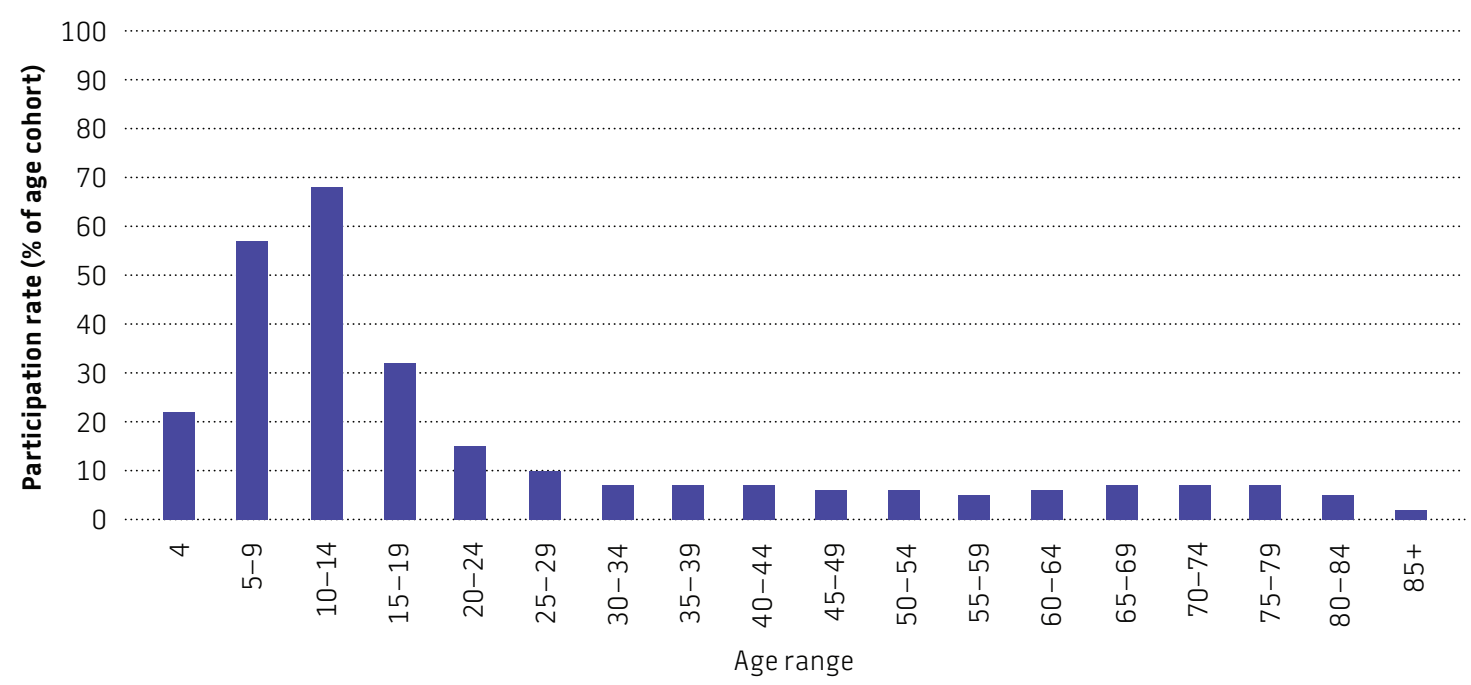

Figure 2. Participation rates, 2017, Victoria: by sex and age

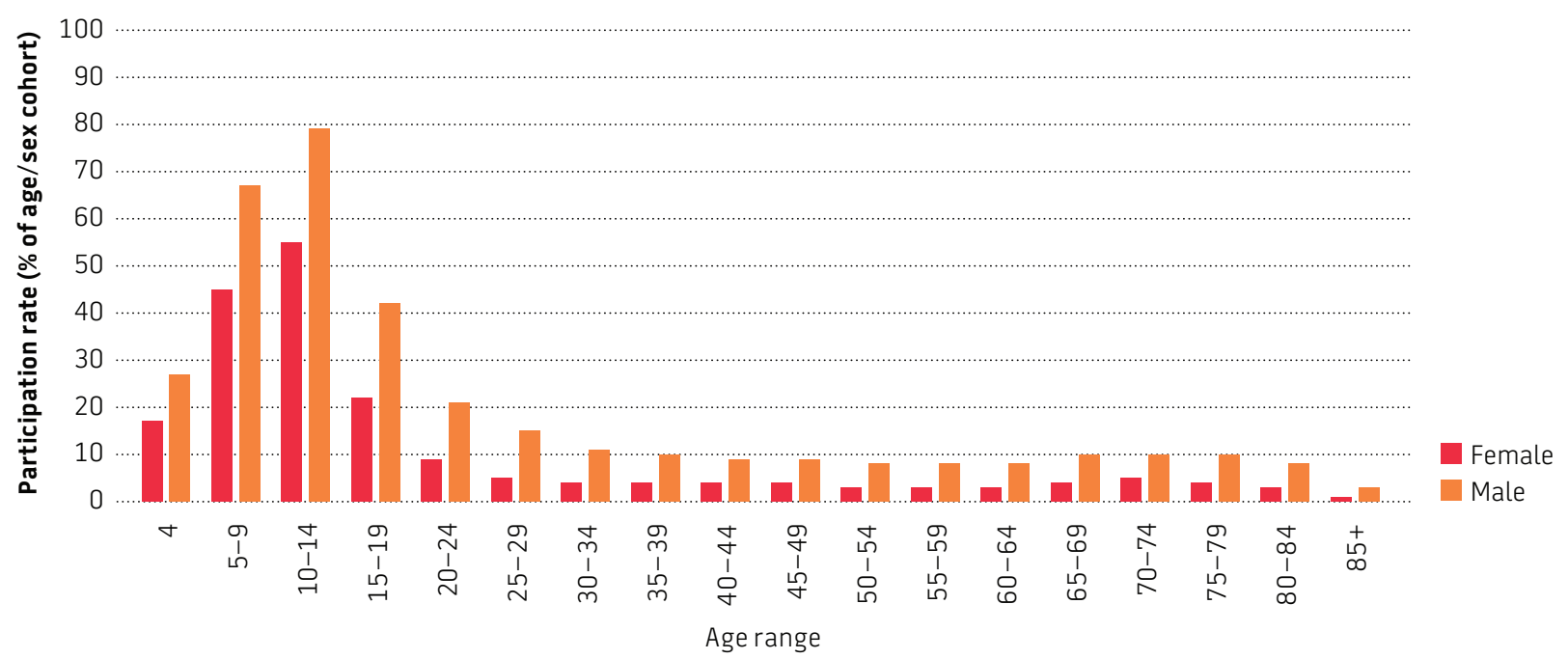

Figure 3. Participation rates, 2017, Victoria: by region and age

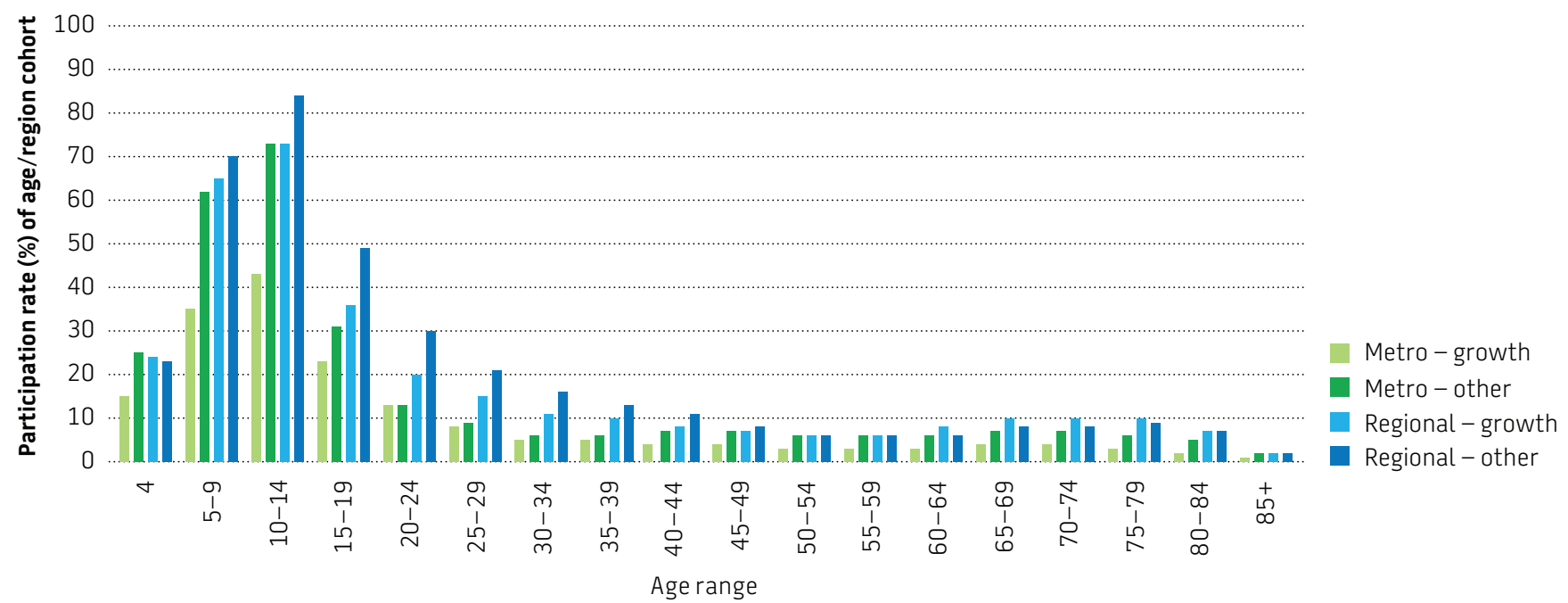


Table 1: Participation rates, 2017, Victoria: by Local Government Area

\begin{tabular}{|c|c|c|c|}
\hline LGA name & $\begin{array}{r}\text { Participation rate }^{1} \\
2017\end{array}$ & LGA name & $\begin{array}{r}\text { Participation rate }^{1} \\
2017\end{array}$ \\
\hline \multicolumn{2}{|l|}{ Metropolitan - growth } & \multicolumn{2}{|l|}{ Regional - other } \\
\hline Cardinia (S) & 15.3 & Alpine (S) & 19.4 \\
\hline Casey (C) & 11.8 & Ararat (RC) & 20.7 \\
\hline Hume (C) & 10.6 & Benalla (RC) & 18.3 \\
\hline Melton (S) & 8.9 & Buloke (S) & 38.6 \\
\hline Mitchell (S) & 14.5 & Campaspe (S) & 23.0 \\
\hline Whittlesea (C) & 10.6 & Central Goldfields (S) & 21.1 \\
\hline Wyndham (C) & 9.6 & Colac Otway (S) & 24.1 \\
\hline \multicolumn{2}{|l|}{ Metropolitan - other } & Corangamite (S) & 29.5 \\
\hline Banyule (C) & 18.8 & East Gippsland (S) & 17.4 \\
\hline Bayside (C) & 29.0 & Gannawarra (S) & 28.9 \\
\hline Boroondara (C) & 22.6 & Glenelg (S) & 23.0 \\
\hline Brimbank (C) & 7.0 & Golden Plains (S) & 18.2 \\
\hline Darebin (C) & 10.9 & Greater Shepparton (C) & 18.1 \\
\hline Frankston (C) & 16.2 & Hepburn (S) & 15.2 \\
\hline Glen Eira (C) & 15.9 & Hindmarsh (S) & 28.0 \\
\hline Greater Dandenong (C) & 5.9 & Horsham (RC) & 24.2 \\
\hline Hobsons Bay (C) & 14.7 & Indigo (S) & 18.3 \\
\hline Kingston (C) & 17.8 & Latrobe (C) & 18.2 \\
\hline Knox (C) & 16.8 & Loddon (S) & 27.4 \\
\hline Manningham (C) & 15.9 & Macedon Ranges (S) & 20.4 \\
\hline Maribyrnong (C) & 9.1 & Mansfield (S) & 20.3 \\
\hline Maroondah (C) & 18.8 & Mildura (RC) & 18.3 \\
\hline Melbourne (C) & 6.9 & Moira (S) & 24.7 \\
\hline Monash (C) & 12.8 & Mount Alexander (S) & 15.6 \\
\hline Moonee Valley (C) & 14.4 & Moyne (S) & 28.7 \\
\hline Moreland (C) & 8.9 & Murrindindi (S) & 17.3 \\
\hline Mornington Peninsula (S) & 22.1 & Northern Grampians (S) & 21.8 \\
\hline Nillumbik (S) & 25.9 & Pyrenees (S) & 18.8 \\
\hline Port Phillip (C) & 11.5 & Queenscliffe (B) & 33.2 \\
\hline Stonnington (C) & 18.0 & South Gippsland (S) & 25.1 \\
\hline Whitehorse (C) & 16.9 & Southern Grampians (S) & 31.6 \\
\hline Yarra (C) & 10.3 & Strathbogie (S) & 18.8 \\
\hline Yarra Ranges (S) & 18.9 & Swan Hill (RC) & 27.8 \\
\hline \multicolumn{2}{|l|}{ Regional - growth } & Towong (S) & 23.2 \\
\hline Ballarat (C) & 17.2 & Wangaratta (RC) & 19.3 \\
\hline Bass Coast $(S)$ & 18.0 & Warrnambool (C) & 24.4 \\
\hline Baw Baw (S) & 20.4 & Wellington (S) & 20.0 \\
\hline Greater Bendigo (C) & 18.8 & West Wimmera (S) & 23.4 \\
\hline Greater Geelong (C) & 17.6 & Wodonga (RC) & 15.1 \\
\hline Moorabool (S) & 16.9 & Yarriambiack (S) & 34.0 \\
\hline Surf Coast (S) & 28.6 & $B=$ Borol & S = Shire. \\
\hline
\end{tabular}

${ }^{1}$ Number of player registrations per 100 residents

Legend: $B=$ Borough, $C=$ City, $R C=$ Rural City, $S=$ Shire. 
Figure 4: Participation rate, by LGA in regional Victoria, 2017

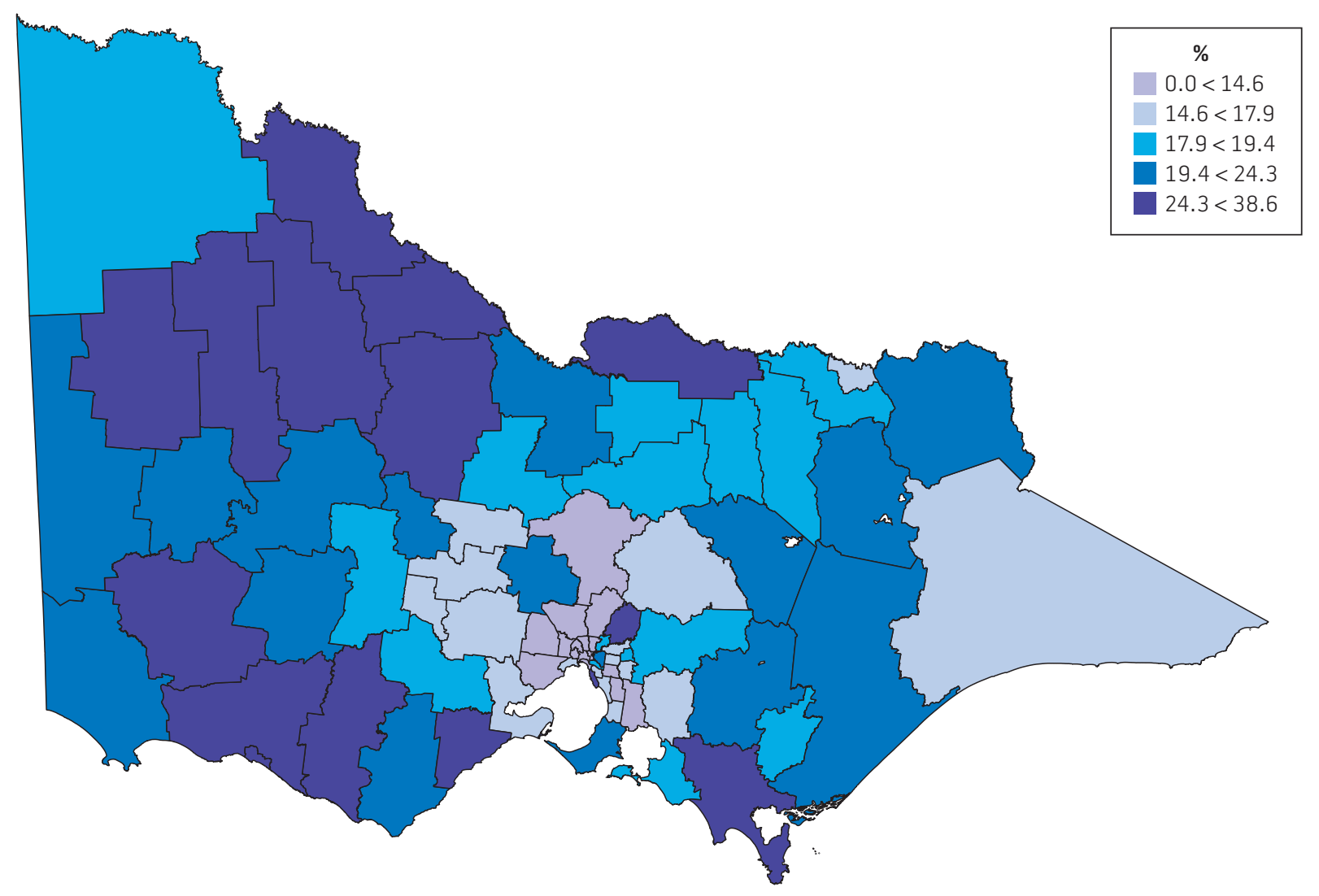

Figure 5: Participation rate, by LGA in Metropolitan regions, 2017

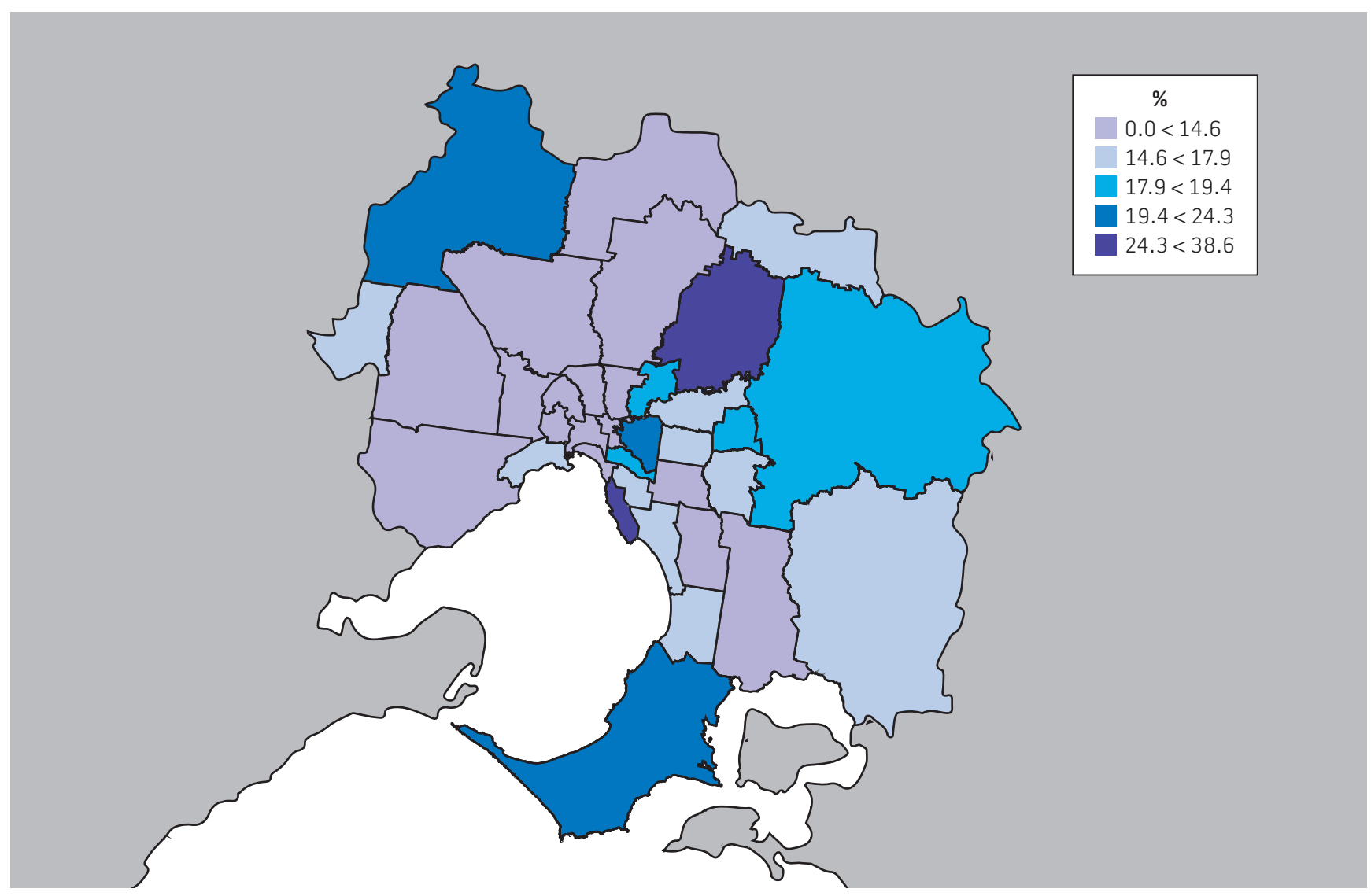




\section{Discussion of key findings 2015-2017}

The 2017 results complete a 3-year program of research from 2015-2017. The key findings are discussed and recommendations are provided.

\section{Participation in sport increased by more than 125,700 participants ( $1 \%$ increase in the participation rate) between 2015-2017. This was approximately equal for male and female participation.}

Key statistics

- Participation numbers in these 12 sports increased by 125,765 from 2015-2017.

- This represented an increase of about 1 percentage point in the participation rate, from $14 \%$ to $15 \%$.

- Male and female rates are of a similar percentage increase.

Sport sector participation policy and strategies are targeted at increasing participation numbers (Department of Health, 2018). Participation in traditional (club) sport has been static or declining in Australia (VicHealth 2018a). It is a positive finding that participation in Victoria increased slightly over the three years. Further increases are going to be contingent upon sport strategic focus areas. This includes investments targeted towards adolescents and adults, as well as building the capacity of the sector including infrastructure, sport specific products and programs, as well as the capacity of club volunteers (Eime and Harvey 2018).

Half of all sports participants are aged between 4-14 years. Sport participation is highest among young children (aged 5-14 years) and drops significantly during adolescence.

\section{Key statistics}

- Overall, sport participation peaked among those aged 10-14 years, with more than two-thirds (68\%) of Victorians within this age group participating in at least one of the 12 sports.

- Half of all sports participants are aged between 4-14 years.

- Overall, sport participation halves from 10-14 (68\%) to 15-19 (32\%) and then halves again for ages 20-24 (15\%).

- The largest growth in participation rates 2015-2017 were within the 10-14 year age group with an increase of $4.6 \%$, followed by $15-19$ years with an increase of $3.1 \%$.

A main focus area of sport policy is to increase participation numbers in sport (Department of Health 2018), and this is often targeted towards children and youth (VicHealth 2018). Therefore, these findings are not surprising. Sports have also historically had a large focus on participation for children through their entry-level modified sports programs for 4-12 year-olds (Eime, Harvey et al. 2018). These programs are designed for the development of sport specific skills in fun and friendly environments with the incorporation of game play but without a main focus on competition and winning.
Historically, the late adolescent years (15-19) is when the largest drop-off in organised sport occurs (Eime and Harvey 2018). This is related to a wide variety of factors including (but not limited to) enjoyment, physical literacy, sport competency, social support, school and work commitments, transition to secondary school, changes in priorities and a general shift in preferences towards non-competitive and unorganised physical activity (Eime, Casey, Harvey, Sawyer et al. 2015, Eime and Harvey 2018). Furthermore, participation in sport and continued participation is also related to socioeconomic status (SES) with those living in higher SES areas more likely to play sport (Eime, Charity et al. 2015, Eime, Harvey et al. 2017).

\section{Sport participation rates among females are half of those among males. From 2015 to 2018 there was a considerable increase in female participation in some traditionally male dominated sports, mainly within the 5-19 year age groups}

\section{Key statistics}

- The participation rate for females (11\%) is half of that among males (20\%).

- There was considerably increased female participation in some traditionally male dominated sports such as AFL, soccer and cricket, mainly within the 5-19 year age groups.

While the overall difference in participation rates for males and females has not changed from 2015-2017 (both increased by about 1 percentage point) there were considerable differences within certain ages and sports. The largest growth in participation overall was in the 10-14 year age group, however for males the largest growth was for 15-19 year-olds and 5-9 year-olds for females.

This is due to policy initiatives and strategic investments by the sports themselves into visible pathways for female athletes (for example investment into AFLW, and cricket's WBBL both televised national leagues for women), and by VicHealth and State Government, for both increasing participation opportunities and improving infrastructure development for females in sport. 


\section{Sport participation rates are higher in regional Victoria compared to metropolitan Melbourne. However, sport participation rates vary considerably within the metropolitan area.}

Key statistics

- Sport participation rates are higher in regional Victoria (20\%) than in metropolitan Victoria (14\%).

- There is lower sport participation in Metropolitan - growth areas (11\%) compared to Metropolitan - other areas (15\%). These rates are lower than Regional - growth areas (19\%) and Regional - other (21\%) areas.

- In general, there are higher participation rates in Melbourne suburbs in the east and south-east compared to the west.

There are many different determinants of participation in sport which relate to individual, social, organisational and environmental contexts (Eime, Casey, Harvey, Sawyer et al. 2015, Eime and Harvey 2018). Some of the explanation of the differences across areas would likely relate to socioeconomic status, the age demographics and provision of and access to sports facilities (Eime, Harvey et al. 2016, Eime, Harvey et al. 2017). Furthermore, the higher participation in nonmetropolitan regions is likely due to the social context of sport and traditional sporting opportunities within these areas, whereas within metropolitan Melbourne there are more choices for other leisure-time pursuits (Eime, Charity et al. 2015).

\section{Participation data collection of sporting organisations can significantly fluctuate in quality both across sports and in the same sport from year to year}

\section{Key statistics}

- In 2017 there was complete participation data for 88\% of records with regard to date of birth, sex and postcode. This has improved slightly from 2015 with $86 \%$ of data having complete participant records.

- Eight sports had good quality data management systems, however 4 sports were lower quality with a higher proportion of missing data for 2017.

- Sports that have changed database providers were more likely to have a year post change over where data quality is significantly reduced.

Some sports have good quality participation data with reasonably complete participant records, however some sports have participation data with missing or inaccurate key information such as age and residential location.

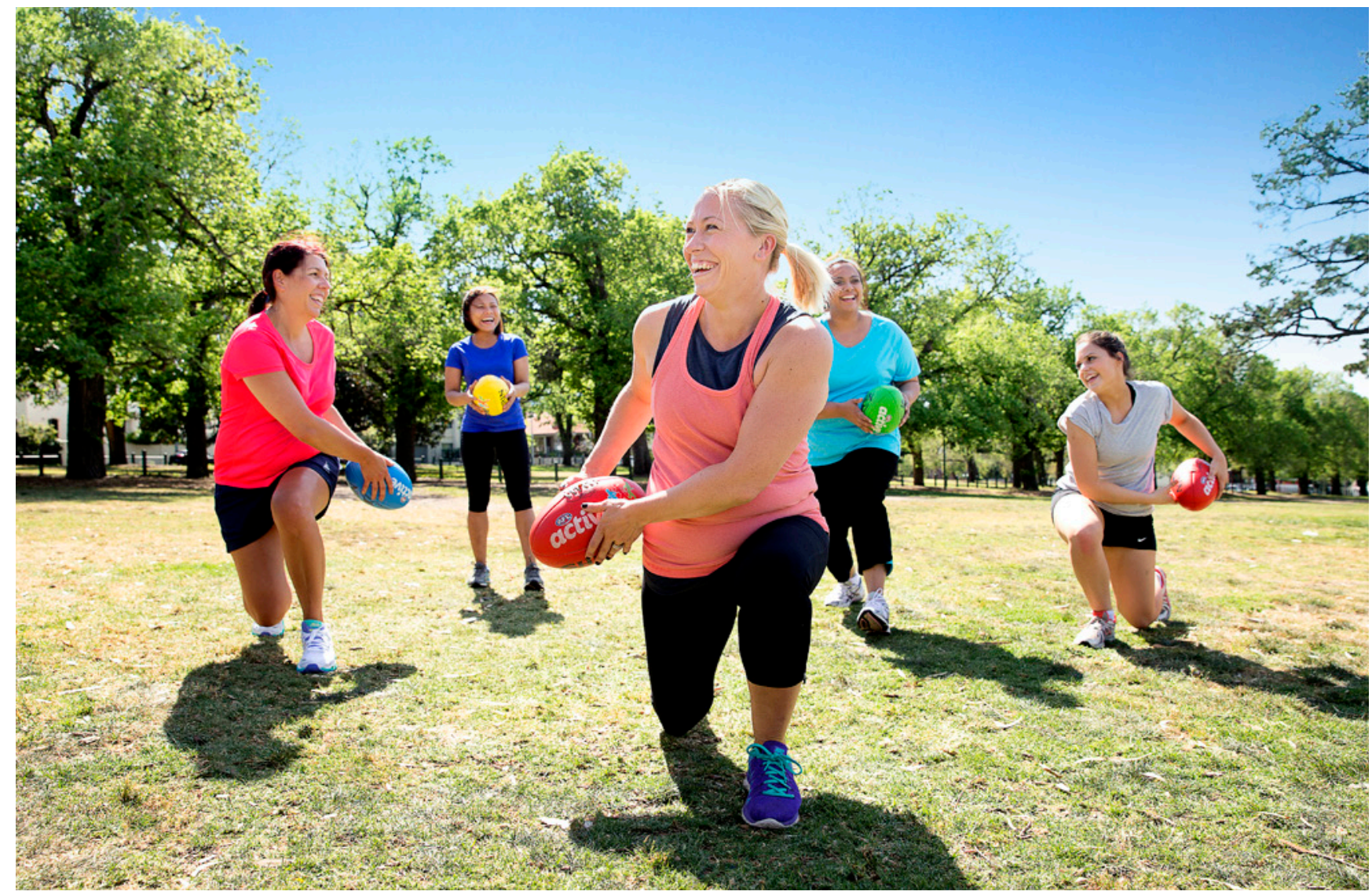




\section{Recommendations}

\section{State Sporting Associations}

\section{Data collection}

That State Sporting Associations:

- review and continually improve the quality of their registered participant databases; for example, to require that each individual participant register their own details online (rather than permitting batch entries of teams) and require the reporting of basic demographic data including date-of-birth, gender identity and postcode

- continue to improve the sophistication of methods of capturing registration details from those who participate in social and/or recreational based programs

- have one integrated participant database system.

Participation

That State Sporting Associations develop/implement:

- strategies and or/programs or playing opportunities suitable for people across the lifespan

- strategies to incorporate skill development regardless of age or sex

- programs or playing opportunities in a range of different formats including competition and other recreational or social formats

- strategies to provide more opportunities for people from low socioeconomic backgrounds to play and continue to play sport

- policy and strategies to increase female participation

- strategies for improving retention in sport, particularly during adolescence

- strategies related to participation in sport for specific demographic groups including those with a disability, people from a non-English speaking background, and Aboriginal and Torres Strait Islanders.

\section{Infrastructure and club capacity}

That State Sporting Associations develop/implement:

- participation strategies that are incorporated with infrastructure planning

- strategies to maximise multi-purpose usage of infrastructure

- strategies for building the capacity of sporting organisations and club volunteers.

\section{Sport policymakers and funding bodies}

Data collection

That policymakers and funding bodies:

- continue data collection, analysis and reporting to inform evidence-based decisions across the sport sector

- consider mandating the collection of a wider scope of basic demographic information

- make analysis and reporting from the Sport Participation Research Project more widely available to local councils and other relevant bodies for use

- ensure the Sport Participation Research Project provide guidance and tips to State Sporting Associations about how to improve data collection.

\section{Participation}

That policymakers and funding bodies develop/implement strategies and policies:

- to provide more opportunities for people from low socioeconomic backgrounds to play and continue to play sport

- to increase playing opportunities in a range of different formats including competition and other recreational or social formats

- to increase female participation

- to increase participation in metropolitan - growth areas, including consideration of infrastructure and club development

- to boost participation opportunities for specific demographic groups including those with a disability, people from a non-English speaking background, and Aboriginal and Torres Strait Islanders.

\section{Researchers}

That further research be conducted into:

- the role that sport can play to improve social and mental health

- trends and determinants in participation and retention

- future sports infrastructure needs, priorities and locations. 


\section{About this research}

Participation in organised sport is associated with a range of physical, social and mental health benefits across the lifespan (Eime, Young et al. 2013, Eime, Young et al. 2013, Jenkin, Eime et al. 2018).

The Sport Participation Research Project has involved the analysis of data on organised participation in 12 major sports over three years, from 2015-2017, and reporting annually on participation levels (number of registered participants and participation rates per head of population) and participation trends, for the Victorian population as a whole, and for various population segments.

The project aims to provide a reliable measure of organised sport participation ${ }^{1}$ in Victoria to inform planning, decision making and investments from State Sporting Associations, all levels of government, funding bodies and sport participation promoters, particularly relating to participation initiatives and facility planning.

\section{About the data}

This analysis reports on 972,927 'participants', or players, aged between 4-100 years, who were registered with a Victorian community sports club or program affiliated with one of the following 12 State Sporting Associations: Australian football, basketball, bowls, cricket, football (soccer), golf, gymnastics, hockey, netball, sailing, swimming, and tennis. It includes participants registered in:

- club competitions

- junior or modified sport programs

(e.g. NetSetGo or AFL Auskick)

- social programs (e.g. Cardio Tennis).

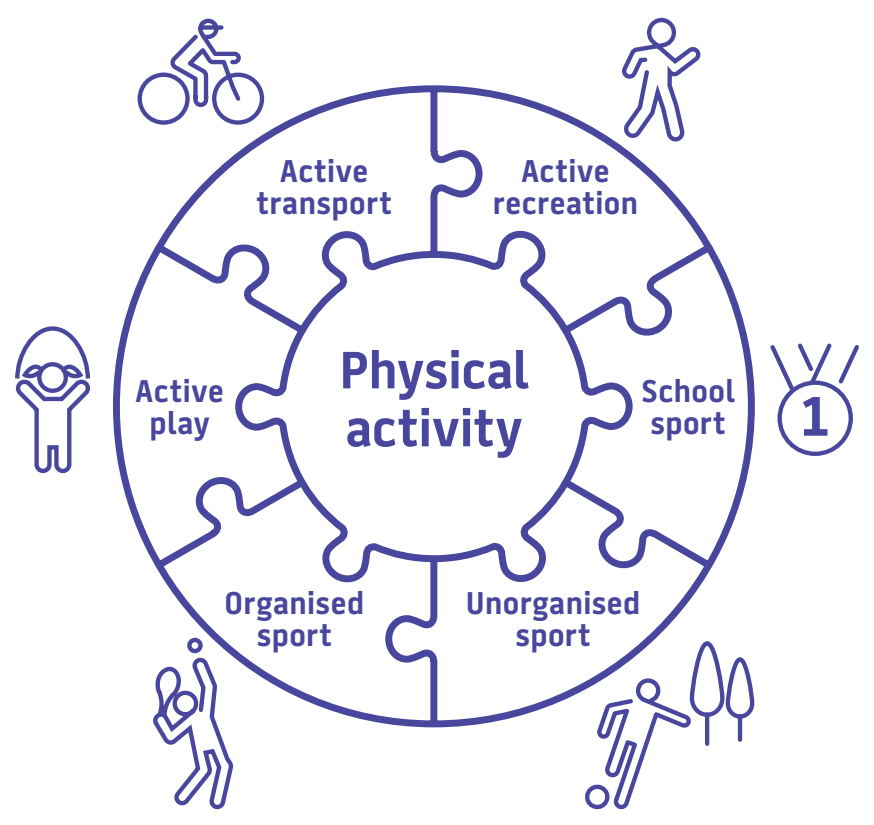

Participation rates are expressed as a percentage of the estimated residential population for each age/sex group (Australian Bureau of Statistics 2017).

Because the data analysed are anonymous, data about individuals who play multiple sports cannot be identified and linked across sports. These individuals are included in the data for each sport they play and therefore are counted multiple times within the overall total.

Reported rates are 'registrations per 100 persons in the relevant population cohort' but are referred to as 'percentages' for simplicity. 


\section{ACKNOWLEDGEMENTS}

The Sport Participation Research Project 2015-2018 was funded by VicHealth and Sport and Recreation Victoria and was conducted by Professor Rochelle Eime, Ms Melanie Charity and Dr Jack Harvey (Victoria University, and Federation University Australia). (www.sportandrecreationspatial.com.au)

The State Sporting Associations involved in this research are: AFL Victoria, Australian Sailing (Victoria), Basketball Victoria, Bowls Victoria, Cricket Victoria, Football Victoria, Golf Victoria, Gymnastics Victoria, Hockey Victoria, Netball Victoria, Swimming Victoria, and Tennis Victoria.

\section{References}

Australian Bureau of Statistics (2017). Population by Age and Sex, Regions of Australia. C. N. 3235.0. Canberra, Australian Bureau of Statistics.

Department of Health (2018). Sport 2030, Commonwealth of Australia: 70.

Eime, R. and J. Harvey (2018). Sport participation across the lifespan: Australian trends and policy implications. Sport and physical activity across the lifespan. R. Dionigi and M. Gard. UK, Palgrave Macmillan: 23-43.

Eime, R., J. Harvey and M. Charity (2016). Age Profiles of Sport Participants - Victoria 2015. Federation University and Victoria University: 1-12.

Eime, R., J. Harvey and M. Charity (2018). Girls' transition from participation in a modified sport program to club sport competition - a study of longitudinal patterns and correlates. BMC Public Health 18(1): 718.

Eime, R., J. Young, J. Harvey, M. Charity and W. Payne (2013). A systematic review of the psychological and social benefits of participation in sport for adults: Informing development of a conceptual model of health through sport. International Journal of Behavioral Nutrition \& Physical Activity 10(135)

Eime, R., J. Young, J. Harvey, M. Charity and W. Payne (2013). A systematic review of the psychological and social benefits of participation in sport for children and adolescents: informing development of a conceptual model of health through sport. International Journal of Behavioral Nutrition \& Physical Activity 10(98).

Eime, R. M., M. M. Casey, J. T. Harvey, M. J. Charity, J. A. Young and W. R. Payne (2015). "Participation in modified sports programs: a longitudinal study of children's transition to club sport competition." BMC Public Health 15(649):

Eime, R. M., M. M. Casey, J. T. Harvey, N. A. Sawyer, C. M. Symons and W. R. Payne (2015). Socioecological factors potentially associated with participation in physical activity and sport: A longitudinal study of adolescent girls. Journal of Science and Medicine in Sport 18(6): 684-690.

Eime, R. M., M. J. Charity, J. T. Harvey and W. R. Payne (2015). Participation in sport and physical activity: associations with socioeconomic status and geographical remoteness. BMC public health 15(434)

Eime, R. M., J. Harvey, M. J. Charity, M. Casey, H. Westerbeek and W. R. Payne (2017). The relationship of sport participation to provision of sports facilities and socioeconomic status: a geographical analysis. Australian and New Zealand Journal of Public Health 41(3): 248-255.

Jenkin, C. R., R. M. Eime, H. Westerbeek and J. G. Z. v. Uffelen (2018). Sport for Adults Aged 50+ Years: Participation Benefits and Barriers. Journal of Aging and Physical Activity 26(3): 363-371.

VicHealth (2018). Physical activity strategy 2018-2023. Retrieved March 9th, 2018, from www.vichealth.vic.gov.au/media-and-resources/publications/ physical-activity-strategy

VicHealth (2018a). Bright Futures report. www.vichealth.vic.gov.au/mediaand-resources/publications/youth-megatrends-report

\section{VicHealth}

\author{
Victorian Health Promotion Foundation \\ P0 Box 154 Carlton South \\ Victoria 3053 Australia \\ $\mathrm{T}+61396671333 \mathrm{~F}+61396671375$ \\ vichealth@vichealth.vic.gov.au \\ vichealth.vic.gov.au \\ twitter.com/vichealth \\ facebook.com/vichealth
}

VicHealth acknowledges the support of the Victorian Government.

(C) VicHealth 2019

October 2019 P-PA-803 